Revista de Economia Política, vol. 33, n 2 (131), pp. 240-259, abril-junho/2013

\title{
Causação circular do crescimento das economias em desenvolvimento: uma ponte entre as abordagens evolucionária e pós keynesiana
}

\author{
DANIELA ALMEIDA RAPOSO TORRES* \\ MARCO FLÁVIO DA CUNHA RESENDE
}

The circular causation of growth in developing economies. Based on the Post Keynesian approach and on the Evolutionary literature, this study seeks to demonstrate the causal relationships between the National Innovation System and the national and international financial systems. This study shows that there is a circular causation in the less developed economies that contributes to the immaturity of its National Innovation System and to its structural external vulnerability. Conclusions highlight that the cycles in the less developed economies mirror the cycles of international liquidity.

Keywords: international liquidity; national innovation system; investment.

JEL Classification: O40; O43.

\section{INTRODUÇÃO}

De acordo com a Escola Evolucionária ${ }^{1}$, o progresso tecnológico é a principal variável explicativa dos diferenciais de crescimento de longo prazo entre economias. Segundo esta escola, o progresso tecnológico é determinado pelas características e grau de desenvolvimento do Sistema Nacional de Inovação (SI) de um país e/ou

\footnotetext{
* Departamento de ciências econômicas da Universidade Federal de São João del-Rei (DCECO/UFSJ, Bolsista do CNPq. E-mail: daniraposo@ufsj.edu.br; Centro de Desenvolvimento e Planejamento Reginal de Minas Gerais da Universidade Federal de Minas Gerais (Cedeplar/UFMG). E-mail: resende@cedeplar.ufmg.br. Submetido: 22/março/2011; Aprovado: 24/maio/2012.

${ }^{1}$ Ver em Nelson e Winter (1982) o desenvolvimento tanto dos antecedentes quanto das premissas básicas da abordagem evolucionária.
} 
região. Logo, o SI de um país é um determinante importante de seu desenvolvimento econômico (Freeman, 1995; Nelson, 1993; Lundvall, 1992).

De outro lado, a Escola pós-keynesiana demonstra que variáveis monetárias interagem com variáveis reais para determinar o produto, o emprego e os preços. Assim, a despeito da relevância do progresso tecnológico para o crescimento econômico, este também é afetado pela interação entre variáveis reais e monetárias na economia monetária de produção. Neste contexto, há na literatura pós-keynesiana indícios de que os ciclos das economias em desenvolvimento são mais aderentes aos ciclos da liquidez internacional do que os ciclos das economias desenvolvidas (Amado, 2003; Resende, 2005; Resende e Amado, 2007; Raposo, 2009).

Este artigo objetiva articular as abordagens evolucionária e pós-keynesiana para explicar a aderência dos ciclos de crescimento dos países em desenvolvimento aos ciclos de liquidez internacional. Pretende-se investigar teoricamente se, por serem distintos os graus de desenvolvimento do SI e do sistema financeiro das economias, há diferentes graus de aderência dos ciclos dessas economias em relação aos ciclos da liquidez internacional. ${ }^{2}$

Conforme Amable e Petit (1999), há na literatura diversos conceitos de SI. Estes podem ser de cunho local, regional ou nacional, como também podem ser restritos ou amplos. Além disso, Amable e Petit (1999 e 2001) demonstram que os SIs são marcados por diversidade e complementaridade de instituições que afetam direta ou indiretamente as inovações e o progresso tecnológico. Deste modo, segundo conclui Fagerberg (1994), cada SI é único, com características e particularidades que conferem a cada SI "um distinto caráter nacional".

Embora exista grande diversidade de SIs, aqueles que apresentam características comuns podem ser classificados em uma mesma categoria, conforme se constata na literatura. Isto é observado em Albquerque (1999), que classifica diversos SIs em apenas três categorias (maduros, imaturos e em catching up), ou mesmo em Amable e Petit (2001), que após discorrerem sobre a heterogeneidade dos SIs apontam quatro principais tipos de Sistemas Sociais de Inovação e Produção e os respectivos países pertencentes a estes tipos.

Para os propósitos deste artigo usaremos a classificação de Albuquerque (1999) que considera como SI maduros aqueles que apresentam taxas de progresso tecnológico superiores aos demais SIs (imaturos) e que se localizam na fronteira tecnológica de alguma(s) área(s) do conhecimento. Isto porque o objetivo deste artigo é demonstrar os efeitos que a vulnerabilidade externa, que decorre de baixas taxas de progresso tecnológico, provoca sobre os ciclos de crescimento da economia a partir das relações causais entre SI, sistema financeiro nacional e sistema financeiro internacional (SFI). ${ }^{3}$

\footnotetext{
${ }^{2}$ Sicsú e Albuquerque (2000 e 2002) são pioneiros na literatura nacional no que se refere à conjugação das abordagens evolucionária e pós-keynesiana,

${ }^{3}$ Especificidades institucionais, tais como a estrutura financeira nacional, o grau de abertura financeira e o regime cambial implicam inserções internacionais de distintas naturezas das economias e, em decor-
} 
O argumento central deste artigo está detalhado ao longo do mesmo, mas, pode ser sintetizado da seguinte maneira: o menor desenvolvimento relativo dos SIs das economias em desenvolvimento eleva a vulnerabilidade externa das mesmas, levando o SFI, que age de modo Minskyano, a classificá-las como economias Especulativas-Ponzi. ${ }^{4}$

De outro lado, as economias em desenvolvimento apresentam deficiências em seu sistema financeiro, em especial a ausência de financiamento privado de longo prazo. São constituídos nestas economias, então, arranjos financeiros que contornam, de modo imperfeito, tais deficiências, viabilizando a sustentação do seu crescimento. Porém, nos períodos de queda cíclica do SFI, tais arranjos financeiros domésticos tornam-se inoperantes (disfuncionais), trazendo à tona as deficiências do sistema financeiro da economia em desenvolvimento. A inoperância desses arranjos financeiros decorre da escassez de divisas externas e/ou da crise cambial nas economias em desenvolvimento (Especulativas-Ponzi), fruto da queda da liquidez internacional e do comportamento Minskyano do SFI. No âmbito do modelo de escolha de ativos de Keynes este processo se manifesta na queda da taxa própria de juros dos ativos associados a elevada incerteza e longo prazo de maturação. Assim, as consequentes quedas do investimento em formação bruta de capital fixo e em inovações tecnológicas se somam para mitigar o amadurecimento do SI, nas economias em desenvolvimento. $\mathrm{O}$ baixo desenvolvimento relativo deste eleva a vulnerabilidade externa da economia, e assim por diante. Há, então, na economia em desenvolvimento, um processo de causação circular que dificulta o amadurecimento de seu SI e torna seus ciclos de crescimento mais aderentes aos ciclos da liquidez internacional vis-à-vis os ciclos da economia cujo SI é maduro.

$\mathrm{O}$ artigo está organizado em cinco seções. $\mathrm{Na}$ segunda seção, está a definição de SI, segundo a literatura evolucionária, como também sua relação com o crescimento econômico. Ainda nesta sessão apresentam-se argumentos teóricos, de cunho pós-keynesiano, necessários para análise e compreensão da relação entre sistema financeiro nacional, SFI e SI. Na terceira seção é apresentado um processo de causação circular, derivado de Resende (2005), para demonstrar o caráter estrutural da vulnerabilidade externa e da imaturidade do SI das economias em desenvolvimento. Na quarta seção, o citado processo de causação circular é ampliado através da construção das relações causais entre SI e sistema financeiro nacional e SFI. Nesta etapa é elaborado um circuito de causação circular, ao qual a economia em desenvolvimento está sujeita, que reúne argumentos teóricos pós-Keynesianos, baseados no modelo de escolha de ativos, e evolucionários, segundo a abordagem do

\footnotetext{
rência, em relações diferenciadas entre o SFI e estas economias e seus respectivos sistemas financeiros nacionais. Embora este nível de detalhamento seja relevante para a compreensão dos ciclos de crescimento das economias em desenvolvimento, sua exploração não é trivial e requer pesquisas futuras e, por isso, foge ao escopo deste artigo.

${ }^{4}$ A vulnerabilidade externa de uma economia pode ser contornada por meio do regime de política econômica. Este parece ter sido o caso do Brasil durante o governo Kubitschek. Porém, esta hipótese é tema para outra pesquisa e foge ao escopo deste artigo.
} 
SI. Conclui-se que na economia onde o SI é imaturo há um processo de causação circular que contribui para perpetuar o caráter imaturo do seu SI como também a aderência de seus ciclos aos ciclos da liquidez internacional.

\section{SISTEMA NACIONAL DE INOVAÇÃO E SISTEMA FINANCEIRO NA ECONOMIA MONETÁRIA: BREVES CONSIDERAÇÕES CONCEITUAIS}

O SI constitui-se no conjunto de características institucionais, sociais e econômicas que um país possui para empreender atividades de inovação e/ou imitação tecnológica. Neste sistema a performance de inovação de uma economia depende não somente da capacidade de inovação tecnológica das firmas individualmente, como também da interação entre elas e o setor financeiro, os centros de pesquisa e o governo. Albuquerque (1999, p.228) define o SI como:

(...) uma construção institucional que impulsiona o progresso tecnológico (...) através da construção de um sistema nacional de inovações, viabiliza-se a realização de fluxos de informação e conhecimento científico e tecnológico necessários ao processo de inovação. Esses arranjos institucionais envolvem firmas, redes de interação entre empresas, agências governamentais, universidades, institutos de pesquisa e laboratório de empresas, bem como a atividade de cientistas e engenheiros: arranjos institucionais que se articulam com o sistema educacional, com o setor industrial e empresarial e com as instituições financeiras, compondo o circuito dos agentes que são responsáveis pela geração, implementação e difusão das inovações tecnológicas. ${ }^{5}$

Ou seja, os diversos SI podem ser descritos a partir das características sociais, econômicas e institucionais que cada país apresenta para desenvolver suas atividades de inovação e difusão tecnológica. A natureza destas interações depende do arcabouço institucional do país, de suas especificidades culturais e históricas, de seu sistema educacional, etc. Portanto, o desenvolvimento do SI de cada país ocorre de modo peculiar e ao seu tempo, de acordo com as especificidades e possibilidades que lhes são apresentadas.

Segundo Albuquerque (1996a, p.230), "a diversidade nacional dos sistemas de inovação é função da variedade de articulações entre seus elementos constituti-

\footnotetext{
${ }^{5}$ Lundvall (1992) propõe um conceito amplo e um restrito de SI. O primeiro corresponde à definição acima, e o segundo envolve apenas as instituições formais de ciência e tecnologia. Freeman (1992), por exemplo, trabalha com o conceito restrito de SI. Nas palavras deste autor (1992, p.173): "The new national systems of innovation (in the narrow sense) comprised university laboratories (...), in house $R \& D$ laboratories in the leading sectors of industry and quality control and testing facilities in other industries, national standards institutes and national research institutes and libraries, a network of national scientific and technical societies and publications (...)".
} 
vos". Os sistemas são diferentes em função: I) da intensidade e organização do $\mathrm{P} \& \mathrm{D}$; II) da organização interna das firmas e do relacionamento inter e intra firmas; do papel das grandes e pequenas empresas no exercício de inovação e difusão tecnológica; III) do papel exercido pelo setor público no fomento das atividades de inovação, via políticas educacionais, industriais, dentre outras, e no financiamento dos gastos com pesquisa; $I V$ ) do papel do setor privado na promoção e financiamento dos gastos em P\&D; V) dos gastos com pesquisa básica e dos gastos militares; VI) do grau de interação entre ciência e tecnologia, isto é, universidade e indústria; VII) dos objetivos do sistema, seja disputar a liderança tecnológica ou reduzir a distância entre líderes e seguidoras via catching up (Nelson, 1993; Lundvall, 1992, Albuquerque, 1996a,B).

Assim, o SI permanece fundamental para o desenvolvimento do progresso técnico e sua difusão em um país (Freeman, 1995; Nelson, 2005; Fagerberg, 1994; Dosi et al. 1994). Portanto, a capacidade de uma economia se desenvolver depende fundamentalmente da organização exitosa do SI. A exemplo disso, os estudos de Freeman (1992 e 1995), Lundvall (1992), Fagerberg e Godinho (2005), e Nelson (1988) relatam e comparam as várias experiências de construção do SI. Estes trabalhos destacam a importância das histórias, das instituições e das culturas dos países $^{6}$ para a definição do perfil e da diversidade desses sistemas.

Albuquerque (1996b, p.57) constrói uma tipologia enumerada em três categorias a partir de características importantes do sistema de inovação. A primeira categoria envolve os sistemas de inovação que capacitam os países a se localizarem na fronteira tecnológica. Este grupo é formado por um conjunto de países denominados líderes, os quais apresentam um SI maduro ${ }^{7}$ capaz de manter o país na liderança do processo tecnológico mundial. A segunda categoria é composta por um conjunto de países cujo objetivo central de seu sistema de inovação é o de promover o crescimento econômico através do processo de difusão tecnológica. Esses países são capazes de absorver, com maior dinamismo, os desenvolvimentos tecnológicos alcançados pelos países líderes e de desenvolver inovações incrementais. A terceira categoria abarca o conjunto de países cujos SIs não foram concluídos, compreendidos, portanto, como imaturos. Em geral, esses países não possuem um sistema cientifico desenvolvido, e, até mesmo quando o possuem, este não é ligado

\footnotetext{
${ }^{6}$ Muitos autores trabalham com a questão da inovação, imitação e difusão sob forte influência histórica e enfatizando outros fatores econômicos, sociais e institucionais para explicar as diferenças entre as taxas de crescimento dos países, a exemplo de Veblen (1915), Gerschenkron (1962), Abramovitz (1986), Maddison (1979, 1982, 1991).

${ }^{7}$ A caracterização de um sistema de inovação em maduro e imaturo está inicialmente proposta em Freeman (1995) e Bell e Pavitt (1993). Estes autores e mais recentemente Albuquerque (1999) e Bernardes e Albuquerque (2003) complementam a análise dos SI, apontando para a maturidade ou não de tais sistemas. Para esses autores, países desenvolvidos, como Japão, EUA, Alemanha, etc., participam do conjunto de países com o SI maduro. Estes seriam os representantes desta primeira categoria. Enquanto países em desenvolvimento, como os integrantes da América Latina, participam do grupo de países com SI imaturo, representando a última categoria. Países como Coréia de Sul, Taiwan e Cingapura participam do grupo de países em processo de catching up, e representariam a categoria mediana.
} 
ao sistema produtivo. Em tais casos, os mecanismos de aprendizado para as empresas nacionais têm sido baseados na importação do conhecimento (importação de tecnologia). Porém, a teoria evolucionária considera impossível a substituição do SI pela importação de tecnologias, tendo em vista o caráter local e tácito assumido pela tecnologia.

Assim, o SI é fundamental para o desenvolvimento das atividades inovativas e de sua difusão/imitação, ou seja, ele determina tanto o sucesso competitivo de um país no cenário internacional quanto de sua sustentação neste ambiente. ${ }^{8}$ Portanto, a formação de um SI maduro é precondição para a conquista de um espaço na fronteira tecnológica e para o desenvolvimento econômico e da competitividade de um país.

De outro lado, a abordagem pós-keynesiana demonstra como as variáveis monetárias interagem com variáveis reais para determinar o produto, o emprego e os preços. Na visão de Keynes (1937, 1983, 1988a, 1988b), na economia monetária de produção o investimento é determinante do produto, emprego e renda. Apenas a decisão de investir é analiticamente importante.

O investimento na economia monetária não depende da poupança, ${ }^{9}$ mas, sim, do finance, que representa, segundo Keynes (1988a e 1988b), o quarto motivo para se demandar moeda. ${ }^{10} \mathrm{O}$ motivo finance pode ser definido como a liquidez que o empresário precisa reter entre o momento em que planeja um determinado gasto de investimento e o momento em que este efetivamente é realizado. O finance dá-se por meio de um fundo rotativo de recursos líquidos - fundo finance, em geral administrado e organizado pelos bancos. A liberação ou a criação de finance é um pré-requisito para o investimento, o que demonstra a relevância do sistema financeiro no processo econômico (Cintra, 1999).

Enquanto o finance tem um caráter de curto prazo, o retorno do investimento é por natureza de longo prazo. Deste modo, quando o finance ocorre, tanto a unidade credora quanto a unidade devedora irão incorrer em aumento de sua vulnerabilidade financeira no curto prazo. Esta vulnerabilidade financeira pode ser mitigada pela mobilização de fundos de longo prazo necessários à consolidação financeira do investimento - trata-se do funding:

Quando o empresário decide investir, precisa estar seguro de dois pontos: primeiro, que pode obter recursos suficientes a curto prazo, du-

\footnotetext{
${ }^{8}$ Ver em Raposo (2009) uma análise detalhada das relações causais entre o grau de desenvolvimento do Sistema Nacional de Inovações e o grau de competitividade de uma economia.

${ }^{9}$ Segundo Keynes (1988b), a determinação do nível de poupança está relacionada com o nível de renda, e não com a taxa de juros. A determinação da taxa de juros não se dá pela igualdade ex ante entre poupança e investimento, pois não existe poupança ex ante e, além disso, em face da incerteza e da preferência pela liquidez, a oferta de dinheiro não é o mesmo que poupança, enquanto a demanda de dinheiro não coincide, necessariamente, com o investimento. A igualdade entre poupança e investimento será ex post e será equalizada pelo nível de renda. Via multiplicador dos gastos, o investimento gera sua própria poupança, não sendo restringido por ela.

${ }^{10}$ Para mais detalhes sobre a teoria da preferência pela liquidez ver Keynes (1983).
} 
rante o período de produção do investimento; e, segundo, que acabará financiando suas obrigações a curto prazo mediante uma emissão de longo prazo, em condições satisfatórias. (Keynes, 1988b, p.336).

Portanto, o funding é necessário para mitigar a ascensão da fragilidade financeira que acompanha o crescimento das economias monetárias. Visando reduzir sua vulnerabilidade financeira, que ocorre no âmbito da materialização das fontes de crédito de curto prazo, as empresas iniciam negociações junto ao mercado financeiro (bancos de investimento, instituições do mercado de capitais), para mobilizar fundos de longo prazo imprescindíveis à consolidação financeira do investimento (Cintra, 1999). Este é o papel da poupança na economia monetária: viabilizar a constituição de fundos de longo prazo requeridos para a consolidação do investimento.

O duplo processo, finance e funding, é dependente da estrutura financeira do sistema econômico. O finance depende de um sistema bancário desenvolvido. $\mathrm{O}$ funding depende da existência de mercados financeiros organizados para comercialização de capitais. Destaca-se a dupla característica deste mercado: o mercado financeiro seria o local onde a instabilidade do sistema se verifica endogenamente e onde essa mesma instabilidade, que ameaça o crescimento da economia, pode ser mitigada (Minsky, 1986). Consequentemente, o mercado financeiro tem papel fundamental, ainda que ambíguo, na sustentação do crescimento econômico (Studart, 1995, pp.58-59).

Portanto, na economia monetária de produção prevalece o circuito financeinvestimento-poupança-funding, no qual o nível de renda é determinado principalmente pelo investimento e, em decorrência do multiplicador da renda, a poupança gerada é exatamente suficiente para se igualar, ex-post, ao investimento. Além disso, os mecanismos de finance-funding são pré-requisitos para geração de investimentos e sua posterior sustentação.

A interação entre os referenciais teóricos pós-keynesiano e evolucionário anteriormente delineados pode ser útil para explicar características dos ciclos de crescimento das economias em desenvolvimento. Esta tarefa será realizada nas próximas seções.

\section{O SISTEMA NACIONAL DE INOVAÇÕES E O PROCESSO DE CAUSAÇÃO CIRCULAR DA ECONOMIA EM DESENVOLVIMENTO.}

Uma primeira aproximação entre as duas tradições teóricas resenhadas neste trabalho - pós-keynensiana e neo-shumpeteriana-, dá-se pela percepção da existência de um processo de causação circular desenvolvido por Resende (2005) e representado pelo fluxograma abaixo. A Figura 1 ilustra um processo de causação circular que permite explicar como o crescimento das economias em desenvolvimento é aderente aos ciclos de liquidez internacional. Além disso, o estudo deste 
processo contribui para o debate sobre as diferenças das taxas de crescimento de longo prazo entre as economias desenvolvidas e em desenvolvimento.

Figura 1: SI e o Processo de Causação Circular nas Economias em Desenvolvimento

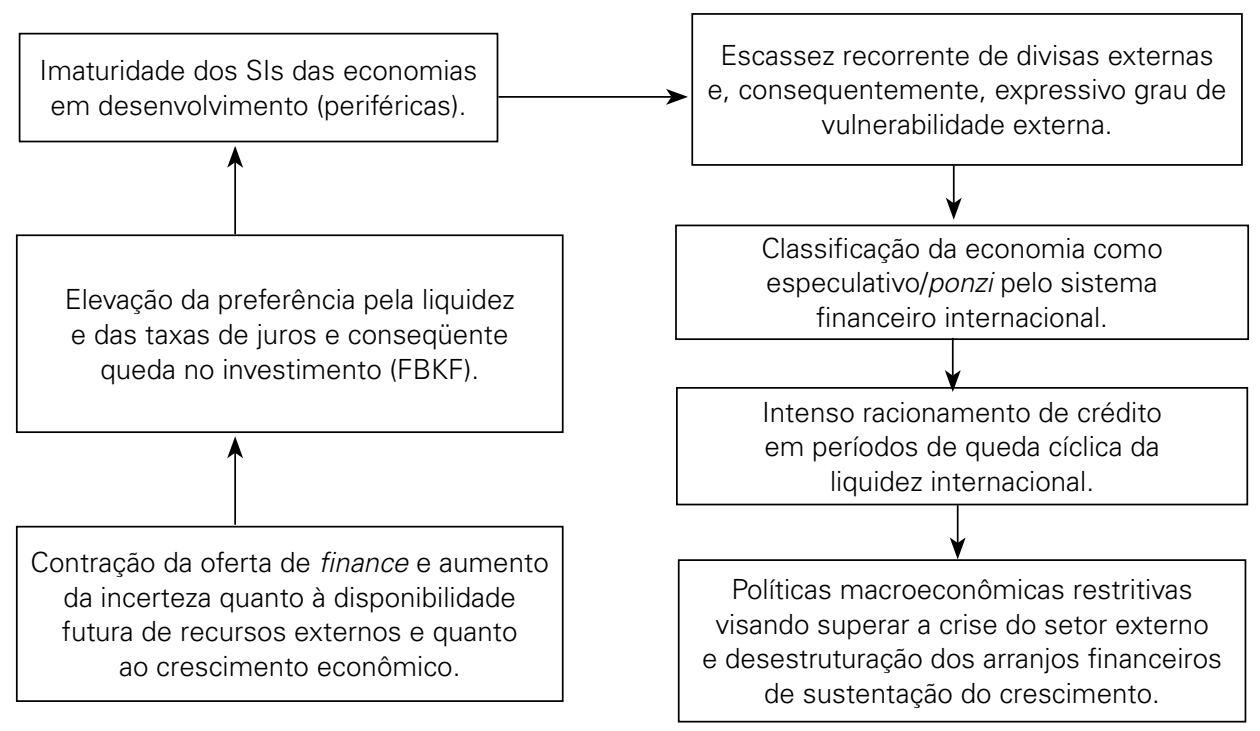

Fonte: Elaboração própria.

Conforme discutido anteriormente, há países cujos SI são pouco desenvolvidos ou imaturos. Albuquerque (1999) demonstrou que tais países correspondem às economias em desenvolvimento. A imaturidade dos SI das economias em desenvolvimento implica elasticidade-renda da demanda de importação superior à elasticidade-renda da demanda de exportação (Resende, 2005; Jayme JR E Resende, 2009). Disto resulta um quadro onde as economias em desenvolvimento tendem a apresentar déficits em transações correntes e, consequentemente, recorrente escassez de divisas externas. Portanto, a economia em desenvolvimento apresenta vulnerabilidade externa de caráter estrutural, pois esta vulnerabilidade está relacionada à estrutura das suas elasticidades-renda de comércio. Este argumento está amparado empiricamente em Raposo (2009).

O efeito da vulnerabilidade externa de uma economia sobre seus ciclos de crescimento pode ser compreendido no âmbito da abordagem minskyana de instabilidade financeira para economias abertas. A abordagem de Minsky (1986) foi elaborada para economias fechadas. Porém, trabalhos como de Lopez (1997), Paula e Alves Jr (2000), Amado (2003), Resende (2005), Resende e Amado (2007) têm procurado fazer o mesmo tipo de análise para a incidência de crises cambiais nos países em desenvolvimento. Neste caso, o sistema financeiro internacional classifica as economias segundo as unidades endividadas de Minsky (1986) — bedge, especulativa e ponzi.

Os países especulativos e ponzi são, segundo Resende (2005), aqueles com 
menor capacidade relativa em gerar o influxo de divisas externas necessário (seja pela balança comercial, de serviços ou capital e financeira) para honrar seus compromissos financeiros internacionais. Sendo assim, Resende e Amado (2007) demonstram que os ciclos das economias em desenvolvimento, isto é, economias especulativas e ponzi, são reflexos dos ciclos da liquidez internacional. Vejamos o argumento.

As economias em desenvolvimento apresentam SI imaturo (Albuquerque, 1999). Deste modo, elas apresentam elasticidade-renda da demanda de importação superior à elasticidade-renda da demanda de exportação e, por isso, elevado grau de vulnerabilidade externa (Raposo, 2009/ Jaymer Jr E Resende, 2009). Portanto, as economias em desenvolvimento são classificadas pelo sistema financeiro internacional como unidades especulativas/ponzi, enquanto as economias desenvolvidas seriam classificadas na categoria hedge, devido a menor capacidade relativa das primeiras de honrar seus compromissos financeiros internacionais. ${ }^{11}$

$\mathrm{Na}$ primeira parte do circuito da Figura 1 (quadrantes superiores), o elevado grau de vulnerabilidade externa das economias em desenvolvimento, que decorre da imaturidade de seus SI, justifica o comportamento minskyano assumido pelo sistema financeiro internacional que as classifica como especulativas/ponzi (Resende, 2005, p.32). Como na economia em desenvolvimento a incerteza sobre sua capacidade de honrar seus compromissos financeiros internacionais é maior, a disponibilidade de crédito é menor vis-à-vis economias desenvolvidas. Porém, nos momentos de ascensão cíclica da liquidez internacional, esta incerteza é amenizada: o otimismo prevalecente no mercado permite a expansão de crédito para as economias classificadas como hedge e, também, especulativas e ponzi. O aumento da entrada líquida de divisas no balanço de pagamentos da economia em desenvolvimento melhora a oferta de finance (Dow, 1986/87), reduz o grau de incerteza (inibindo a preferência pela liquidez, as taxas de juros domésticas e estimulando o investimento), corrige possíveis situações de escassez de divisas externas e esconde sua vulnerabilidade externa, afastando momentaneamente a restrição externa ao seu crescimento.

Entretanto, nos períodos de queda cíclica da liquidez internacional o otimismo se desfaz e há uma restrição de crédito mais intensa, ou assimétrica, para essas economias, dada a incerteza relativamente maior sobre sua capacidade de honrar seus compromissos financeiros internacionais. Consequentemente, a incerteza sobre

\footnotetext{
${ }^{11}$ Resende (2005) argumenta que as economias que apresentam menor desenvolvimento relativo de seus SI, se caracterizam por uma inserção internacional pouco competitiva e por baixa atração de capitais (pois as taxas de retorno do investimento são relativamente baixas). Consequentemente, surge nessas economias uma escassez crônica de divisas externas implicando, para as mesmas, elevado grau de vulnerabilidade externa. Ou seja, a menor capacidade relativa dessas economias de gerar entrada líquida de divisas externas deve-se a uma característica do seu lado real, a saber, o menor desenvolvimento relativo de seus SI. Ademais, conforme demonstra Albuquerque (1999), as economias que apresentam os menores graus de desenvolvimento de seus SI são as economias em desenvolvimento. Portanto, estas economias são aquelas classificadas como especulativas/ponzi pelo sistema financeiro internacional.
} 
a disponibilidade futura de divisas externas e de finance cresce na economia em desenvolvimento num contexto de dificuldades de balanço de pagamentos. $\mathrm{O}$ aumento da incerteza provoca o aumento da preferência pela liquidez, que na economia em desenvolvimento é satisfeita por meio da demanda de divisas externas (Dow, 1999, pp. 154-155), reforçando a percepção do sistema financeiro internacional sobre a sua posição especulativa ou ponzi. Deste modo, a vulnerabilidade externa dessas economias é evidenciada nos períodos em que a liquidez internacional encontra-se deprimida. Tais períodos são recorrentes já que na abordagem minskyana os mercados financeiros apresentam um comportamento cíclico endógeno. Uma vez que a manifestação da escassez de divisas externas nas economias em desenvolvimento está estreitamente atrelada à queda cíclica da liquidez mundial, ,seu crescimento torna-se mais dependente dos ciclos de tal liquidez quando comparado ao crescimento dos países desenvolvidos. Portanto, as economias em desenvolvimento se comportam de maneira reflexiva com relação aos ciclos de liquidez internacional, conforme evidenciado pelo circuito da Figura 1 e argumentado em Amado (2003), Resende e Amado (2007), entre outros.

Ainda na segunda parte do circuito, identificado pelos quadrantes inferiores da Figura 1, a escassez de divisas externas que decorre do racionamento de crédito mais elevado para a economia especulativa/ponzi resulta em crise do seu setor externo. Políticas macroeconômicas restritivas adotadas visando a superação da crise externa desestruturam os arranjos financeiros alternativos aos mecanismos tradicionais de finance-funding, requeridos para o financiamento e sustentação do crescimento (Resende, 2005). Conforme Studart (1995), em poucas economias (países anglo-saxões) o circuito finance-investimento-poupança-funding verifica-se nos moldes elaborados em Keynes. Nas demais economias desenvolveram-se arranjos financeiros alternativos aos mecanismos tradicionais de finance-funding visando a sustentação do crescimento. Ou seja, nos países em desenvolvimento há graves lacunas no sistema financeiro doméstico com destaque para a ausência de financiamento privado de longo prazo. Studart (1995) mostrou que nestes países surgem, então, mecanismos alternativos de finance-funding para viabilizar o crescimento econômico e sua sustentação. Resende (2005) também estudou estes mecanismos alternativos para o caso do Brasil. É neste contexto que estão sendo usados neste artigo os termos "mecanismos tradicionais" e "mecanismos alternativos" de finance-funding. ${ }^{12}$

No âmbito deste processo verifica-se a contração da oferta de finance (elemento fundamental para se detonar o investimento) e o aumento da incerteza quanto

\footnotetext{
${ }^{12}$ No caso do Brasil, por exemplo, os arranjos financeiros alternativos aos mecanismos tradicionais de finance-funding apresentam três modalidades distintas: I) autofinanciamento das empresas pelo mecanismo de majoração de seus mark ups; II) fundos públicos, compostos, principalmente, pelos fundos do Banco Nacional de Desenvolvimento Econômico e Social (BNDES) e Banco do Brasil; III) recursos externos através do acesso a capitais do exterior. A articulação dessas modalidades dá-se pela ação das políticas econômicas de financiamento, tributária, fiscal, cambial, monetária, etc. Para mais detalhes ver Studart (1995) e Resende (2003, 2005).
} 
à solvência externa do país e ao crescimento econômico. Este aumento da incerteza resulta em aumentos da preferência pela liquidez. Consequentemente há uma elevação das taxas de juros e uma diminuição nos retornos esperados dos projetos de investimento nas economias em desenvolvimento. Assim, o investimento se reduz, provocando a reversão do ciclo de crescimento.

Neste ponto, Nelson (2005) e Dosi et al. (1994) demonstram que o investimento em capital fixo é condição necessária, embora não suficiente, para o desenvolvimento do SI e para o êxito do processo de catching $u p \cdot{ }^{13}$ Sendo a formação bruta de capital fixo condição necessária para o desenvolvimento do SI, nos períodos de queda cíclica da liquidez internacional o investimento encontra-se deprimido na economia em desenvolvimento e o SI desses países encontra dificuldades para desenvolver-se, o que prejudica a inserção competitiva dos mesmos no mercado internacional e impossibilita seu crescimento sustentável, e assim sucessivamente. Há, então, na economia em desenvolvimento um processo de causação circular que tende a perpetuar o baixo grau de desenvolvimento relativo de seu SI e, também, as características de seu crescimento, expressas no elevado grau de aderência de seus ciclos aos ciclos da liquidez mundial.

Uma forma das economias em desenvolvimento romperem com o circuito apresentado dar-se-ia pelo amadurecimento de seus SI. O desenvolvimento relativo do SI dessas economias aliviaria a restrição externa ao seu crescimento de maneira sustentada (permanente), reduzindo o grau de dependência de seus ciclos aos ciclos da liquidez mundial e rompendo o processo de causação circular da Figura 1. O amadurecimento do SI de uma economia ensejaria ganhos permanentes e continuados de competitividade, o que reduziria o grau de sua vulnerabilidade externa.

Embora o citado processo de causação circular esteja demonstrado em Resende (2005), este autor explica a perpetuação do baixo desenvolvimento relativo do SI das economias em desenvolvimento com base apenas nas taxas de investimento em capital fixo, entendidas como condição necessária para o desenvolvimento do SI. Este trabalho busca completar sua análise, ao incorporar outros elementos que caracterizam um SI, descritos na seção anterior. Em outras palavras, o investimento em formação bruta de capital fixo (FBKF) é apenas um dos muitos elementos requeridos para o desenvolvimento do SI. Ele é, portanto, apenas condição necessária, mas não suficiente, para explicar o baixo desenvolvimento relativo do SI das economias em desenvolvimento. ${ }^{14}$

Outro ponto de articulação entre as duas tradições teóricas resenhadas nesse trabalho (pós-keynensiana e neo-shumpeteriana), dar-se-ia pela ausência de um sistema financeiro doméstico desenvolvido nas economias em desenvolvimento.

\footnotetext{
${ }^{13}$ Sobre o processo de catching up ver Gerschenkron (1962) e Abramovitz (1986).

${ }^{14}$ Note-se que para Schumpeter é a partir do investimento que os empresários podem obter lucros, e parcela desses lucros é reinvestida em atividades inovativas. Logo, também para este autor o investimento é uma variável fundamental na explicação do progresso tecnológico, dos ganhos de produtividade e do crescimento econômico.
} 
Assim, a escassez de financiamento de longo prazo implica a necessidade de se construir arranjos financeiros alternativos aos mecanismos tradicionais de finance-funding. Porém, tendo em vista as limitações competitivas das economias em desenvolvimento decorrentes da imaturidade de seu SI, os períodos de queda cíclica da liquidez internacional desembocam, recorrentemente, em crises cambiais nas economias em desenvolvimento. Para contornar as crises, a política macroeconômica adotada destrói a funcionalidade desses arranjos financeiros que financiam e servem de suporte ao crescimento econômico, provocando uma reversão da fase ascendente do ciclo de crescimento dessas economias (Resende, 2005).

Este resultado permite-nos inferir sobre a capacidade desses arranjos financeiros alternativos de fornecerem recursos, suficientes e em condições adequadas, para suprir as necessidades financeiras de atividades entendidas como de elevado prazo de maturação e alta incerteza, como a FBKF e as atividades inovativas.

Em resumo, as deficiências do SI dos países em desenvolvimento devem-se, entre outros fatores, à elevada restrição de financiamento, seja pela ausência de um sistema financeiro doméstico desenvolvido, ou pela inoperância dos arranjos financeiros alternativos em períodos de queda cíclica da liquidez mundial. ${ }^{15}$ Isso porque os elevados custos e incerteza inerentes ao processo de FBKF e ao universo tecnológico acentuam-se na ausência de um sistema financeiro desenvolvido, caracterizado por mecanismos de finance e de funding que ensejam as condições necessárias ao financiamento de longo prazo. Neste ponto, Sicsú e Albuquerque (2000 e 2002), pioneiros na literatura nacional na conjugação das abordagens evolucionária e pós-keynesiana, sugerem a construção de uma Agência Especial de Seguros (AES) ${ }^{16}$ como forma de estimular o engajamento do sistema bancário privado brasileiro no financiamento do investimento inovativo. O resultado de sucesso da implementação dessa entidade seria a redução da incerteza dos agentes a ponto de viabilizar as operações de finance do setor privado no investimento em atividade de ciência e tecnologia. Ademais, o funcionamento bem sucedido da AES ao ampliar a diversidade de iniciativas inovadoras e fortalecer a dinâmica evolutiva das economias contribuiria para a redução das diferenças das taxas de crescimento de longo prazo entre as economias desenvolvidas e em desenvolvimento.

A relação entre o sistema financeiro e o desenvolvimento do SI nas economias em desenvolvimento será demonstrada, neste artigo, através do modelo de escolha de ativos de Keynes. Esta tarefa será realizada a seguir.

\footnotetext{
15 O estudo dessa relação sistêmica teria como ponto de partida uma análise das características de financiamento às inovações nos países desenvolvidos, trabalhadas, por exemplo, em Hall (2002) e Carpenter e Petersen (2002). Contudo, essa análise ultrapassa o escopo deste trabalho.

${ }^{16}$ Em Sicsú e Albuquerque (1998) observa-se a idealização de uma AES dos financiamentos a atividade inovativa. A necessidade da AES decorre das especificidades do investimento em atividades em pesquisa e desenvolvimento, embuidas, conforme destacado anteriormente, de um elemento de incerteza, sendo que o grau de incerteza das mesmas varia de acordo com o tipo de inovação (no intervalo entre radical e incremental).
} 


\section{O PROCESSO DE CAUSAÇÃO CIRCULAR DO SISTEMA NACIONAL DE INOVAÇÕES IMATURO NO ÂMBITO DO MODELO DE ESCOLHA DE ATIVOS}

Nesta seção será elaborada a partir do modelo de escolha de ativos de Keynes e da ampliação do circuito de causação circular anteriormente apresentado, uma explicação para a perpetuação do caráter imaturo do SI das economias em desenvolvimento. De acordo com tal modelo, toda a classe de ativos existentes na economia, inclusive moeda, apresenta sua taxa própria de juros, definida pela soma: $a+q-c+$ $l$, onde $q$ é o rendimento esperado do ativo, $c$ o custo de sua retenção, $a$ é a sua valorização esperada de mercado e $l$ seu prêmio de liquidez. ${ }^{17}$ No caso da moeda pode-se considerar $a, q$ e $c$ iguais ou próximos de zero. Assim, a sua taxa própria de juros é praticamente dada por $l$, ou seja, pelo prêmio de liquidez. Ademais,

(...) a preferência pela liquidez é refletida em termos do trade off entre retornos monetários $(a+q-c)$ e o prêmio de liquidez da moeda $(l)$, causando assim substituições na estrutura de demanda por ativos, que se diferenciam de acordo com combinações de retornos monetários e prêmio de liquidez que oferecem, sendo a liquidez valorizada quando a incerteza aumenta (Paula, 1999, p.176).

Por fim, dado o estado das expectativas, o agente alocará sua riqueza no ativo com maior taxa de juros própria. Mudanças nas expectativas quanto ao futuro e no grau de confiança nessas expectativas afetam de modo desigual os valores de $q$, $a, c$ e $l$ dos diversos tipos de ativos - dos mais líquidos aos menos líquidos. Tais mudanças provocam então alterações na conformação do portfólio dos agentes, que no processo de alocação da sua riqueza buscam os ativos com as maiores taxas próprias de juros.

Num ambiente de incerteza, os bancos, assim como os demais agentes da economia monetária, têm preferência pela liquidez. A sua escala de preferência pela liquidez varia segundo o grau de incerteza e confiança nas expectativas quanto ao retorno esperado dos diversos ativos. Sua estratégia de maximização de ganhos defini-se de acordo com o trade-off entre rentabilidade $(a+q-c)$ e liquidez $(l)$. Deste modo, no âmbito do modelo de escolha de ativos, o sistema financeiro prefere liquidez à rentabilidade; em outras palavras, escolherá ativos mais líquidos para compor seu portfólio de aplicações, em função de maior incerteza sobre as condições que vigorarão no futuro. Assim, em um contexto de elevada incerteza, teríamos:

$$
\mathrm{q}_{\mathrm{m}}+\mathrm{a}_{\mathrm{m}}-\mathrm{c}_{\mathrm{m}}+\mathrm{l}_{\mathrm{m}}>\mathrm{q}_{\mathrm{k}}+\mathrm{a}_{\mathrm{k}}-\mathrm{c}_{\mathrm{k}}+\mathrm{l}_{\mathrm{k}},
$$

onde $m=$ ativo de elevada liquidez, como a moeda; e $k=$ ativo ilíquido, como bens de capital; ou seja, a taxa própria de juros de $m$ é superior à taxa própria de

\footnotetext{
${ }^{17}$ Para mais detalhes sobre a Teoria de Escolha dos Ativos, ver Carvalho (1992, cap. 5), Paula (1999) e Keynes (1983, cap.17).
} 
juros de $k$, levando os agentes a recomporem seu portfólio de aplicações em direção a $m$ e em detrimento de $k$.

Alternativamente, ao buscar rentabilidade em detrimento de liquidez, os agentes escolherão ativos menos líquidos ou de maior retorno/risco quando as expectativas são otimistas e a incerteza baixa. Neste caso, teríamos:

$$
\mathrm{q}_{\mathrm{m}}+\mathrm{a}_{\mathrm{m}}-\mathrm{c}_{\mathrm{m}}+\mathrm{l}_{\mathrm{m}}<\mathrm{q}_{\mathrm{k}}+\mathrm{a}_{\mathrm{k}}-\mathrm{c}_{\mathrm{k}}+\mathrm{l}_{\mathrm{k}},
$$

quando, então, a alocação da riqueza dos agentes se daria em direção a $k$ e em detrimento de $m$. Ou seja, quando as expectativas e a confiança no futuro são favoráveis, o peso que os agentes conferem ao prêmio de liquidez é reduzido, o que significa dizer que eles são estimulados a empregar sua riqueza em ativos menos líquidos mas com maior retorno pecuniário esperado, pois enxergam que sua taxa própria de juros é maior do que a de um ativo de alta liquidez, como a moeda.

Em países cujo SI é maduro, os estímulos ao progresso tecnológico, ao crescimento econômico, à elevação da produtividade e aos ganhos de competitividade são maiores em relação a países com SI pouco desenvolvido (imaturo). Em função disto, o sistema financeiro forma expectativas mais otimistas quanto ao retorno de seus empréstimos nos países com SI maduro quando comparado ao caso dos países com o SI imaturo. Neste ambiente de expectativas otimistas, o atributo rentabilidade tende a superar o atributo de liquidez de um ativo, decorrente da queda do seu prêmio de liquidez (1) em relação ao retorno pecuniário esperado $(a+q-c)$. Então, na comparação entre as diversas taxas próprias de juros, resulta maior a taxa própria de juros dos ativos que oferecem rentabilidade mais elevada em relação à taxa própria de juros dos ativos que oferecem maior liquidez, quando a incerteza é baixa e o otimismo é alto. Assim, como o sistema financeiro alocará sua riqueza no ativo com maior taxa de juros própria, prefere, neste caso, a rentabilidade à liquidez, procurando optar pela compra de ativos de menor liquidez, mas com maior rentabilidade e com prazos de maturação mais longos.

Em resumo, no âmbito do modelo de escolha de ativos, o sistema financeiro nacional e/ou internacional busca maximizar seus ganhos a partir do trade-off entre liquidez e rentabilidade. Deste modo, quanto maior é o desenvolvimento do SI, menor é a incerteza e maior é a taxa própria de juros dos ativos que oferecem rentabilidade mais elevada, prazos de maturação maiores e menor liquidez, em relação àqueles que oferecem menor rentabilidade e maior liquidez.

Assim, na presença de um SI mais desenvolvido a incerteza tende a ser baixa e bancos e o sistema financeiro em geral modificam sua estrutura de demanda por ativos em favor da compra de ativos de maior risco (quanto ao retorno do capital) e ilíquidos (por serem empréstimos de mais longo termo), dentre os quais estão aqueles ligados ao financiamento da FBKF e das atividades inovativas. ${ }^{18}$ Em res-

\footnotetext{
${ }^{18} \mathrm{O}$ investimento em atividades inovativas tem um elemento de incerteza, e o grau de incerteza das mesmas varia de acordo com o tipo de inovação (no intervalo entre radical e incremental). Apesar desta diferenciação, o processo de introdução de qualquer um destes tipos de inovação pode ser entendido como uma escolha de portfólio, variando segundo as características essenciais do investimento em ativos físicos: incerteza (quanto ao retorno) e iliquidez (antes mesmo da introdução da inovação, gastos com
} 
posta ao financiamento a estas categorias de atividades há um maior desenvolvimento do SI. Ao contrário, nos países onde o SI é imaturo, o crescimento econômico é caracterizado pela escassez recorrente de divisas externas e elevado grau de aderência aos ciclos da liquidez internacional, o que denota elevada incerteza e menor grau de confiança nas expectativas quanto ao futuro. Como resultado, surge um desestímulo ao investimento em FBKF e em ativos inovativos e, portanto, ao desenvolvimento do SI, ampliando o hiato de desenvolvimento entre os SI das economias desenvolvidas e em desenvolvimento.

A interação entre o sistema financeiro e o investimento em FBKF e em ativos inovativos nas economias com SI imaturo está representada pelo fluxograma da Figura 2. Este fluxograma corresponde ao círculo vicioso elaborado em Resende (2005, e Figura 1) e ampliado pelo papel que o sistema financeiro exerce para o amadurecimento do SI.

No fluxograma anterior (Figura 1), a queda cíclica da liquidez mundial resulta em aumento da incerteza e da preferência pela liquidez na economia com SI imaturo em um nível mais elevado do que nas demais economias. Ao longo deste processo observa-se a escassez de divisas externas e a contração da oferta de finan$c e$ de forma mais acentuada nas economias em desenvolvimento vis-à-vis as economias desenvolvidas. Observa-se, também, a desestruturação dos arranjos financeiros que se constituíam em alternativa para o financiamento de longo termo - o sistema financeiro da economia em desenvolvimento apresenta uma lacuna, qual seja o financiamento privado de longo prazo (Studart, 1995). Tanto a escassez de divisas externas e a contração da oferta de finance, como também a desfuncionalidade dos arranjos alternativos de financiamento de longo prazo levam ao aumento da incerteza e da preferência pela liquidez. O resultado é, segundo Resende (2005), o aumento da taxa de juros e a queda do investimento em FBKF, o que inibiria o desenvolvimento do SI. Contudo, este autor não demonstrou este processo no contexto do modelo de escolha de ativos. Ao fazê-lo, torna-se possível explicitar um problema especificamente financeiro, presente no processo de (não) amadurecimento dos SI das economias em desenvolvimento.

$\mathrm{O}$ aumento da incerteza nestas economias que decorre da queda cíclica da liquidez mundial implica elevação da taxa própria de juros dos ativos de maior liquidez em relação aos ativos ilíquidos. No âmbito do modelo de escolha de ativos o investimento em FBKF se contrai, prejudicando o desenvolvimento do SI, conforme está representado na Figura 1. O fluxograma da Figura 1 pode ser ampliado

P\&D são realizados, não havendo possibilidade de reversão desta decisão sem custos). Sob essa perspectiva, inovações radicais e pesquisas básicas apresentam elevado grau de incerteza e iliquidez em relação ao menor grau expresso em inovações incrementais. É importante notar, entretanto, que essas características (incerteza e iliquidez) podem ser reduzidas (no intervalo entre os tipos de inovação), mas nunca eliminadas. Segundo Dosi (1988, p.1134) apud Crocco (2006, p.121), "even when the fundamental knowledge base and the expected directions of advance are fairly well known, it is still often the case that one must first engage in exploratory research, development, and design before knowing what the outcome will be (...) and what some manageable results will cost, or, indeed, whether very useful results will emerge". 


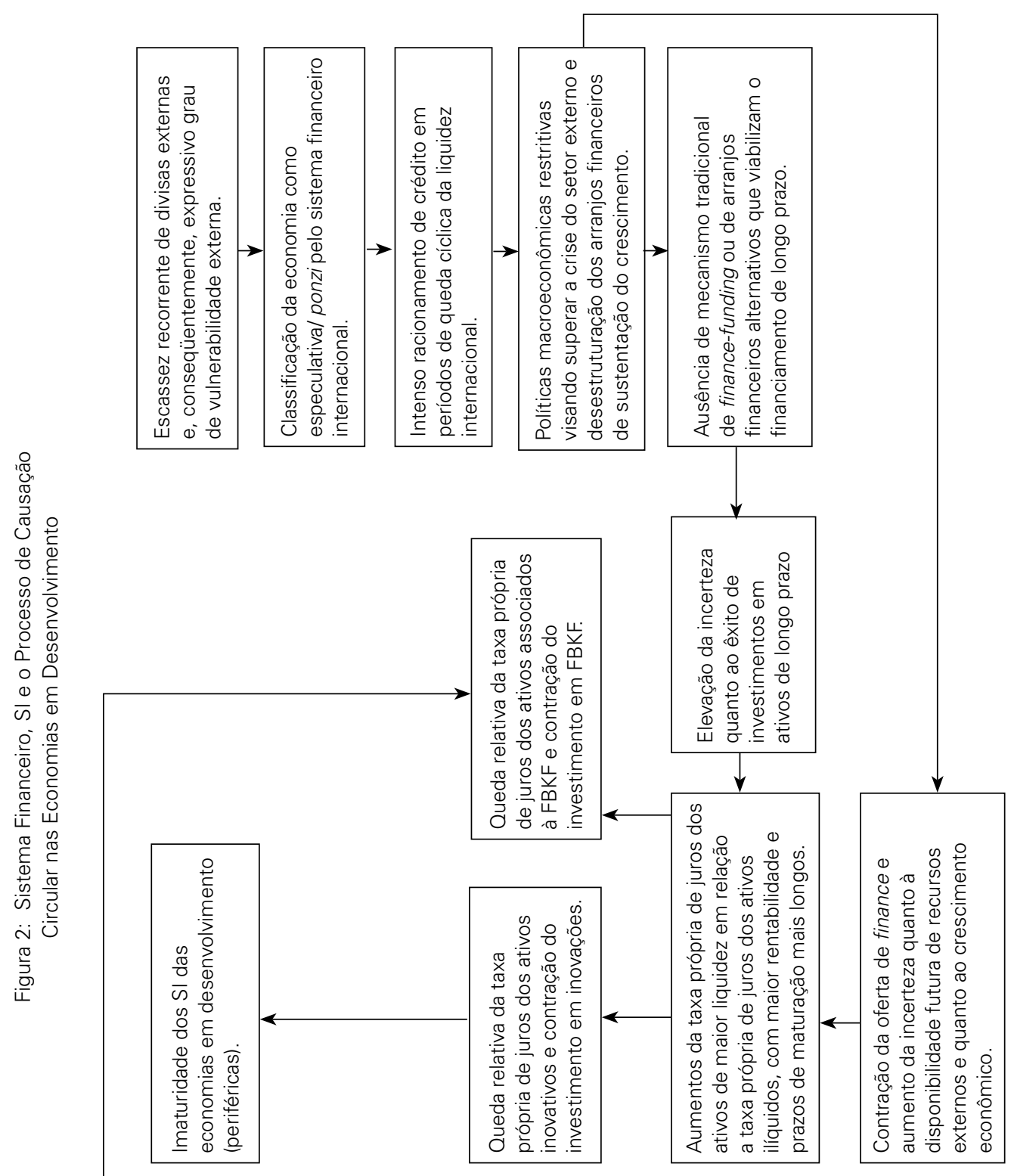


considerando-se que, neste processo, o aumento da incerteza leva, ainda, à queda da taxa própria de juros dos diversos tipos de ativos sem liquidez. Isto provoca a contração do investimento em ativos inovativos, pois estes também são de reduzida liquidez, contribuindo para inibir o amadurecimento do SI.

Este processo é reforçado por um problema especificamente financeiro das economias em desenvolvimento. Nestas, a ausência de um sistema financeiro doméstico desenvolvido, onde estejam estabelecidos mecanismos de finance e de funding adequados ao financiamento privado de longo prazo (Studart, 1995), eleva ainda mais a incerteza associada às atividades com horizonte temporal de longo termo. Este é o caso da FBKF e do investimento em inovações tecnológicas. Ou seja, a incerteza natural ligada a atividades de longo prazo (como, por exemplo, investimento em FBKF e ativos inovativos) é amplificada na ausência de um sistema financeiro doméstico desenvolvido. Por exemplo, o agente que investe em ativos inovativos não sabe se conseguirá fazer o funding se o sistema financeiro não é desenvolvido e não apresenta as condições adequadas de funding. Isto provoca, então, uma queda ainda maior da taxa de juros própria do ativo inovativo.

Contudo, nos períodos de crescimento da liquidez internacional as deficiências do sistema financeiro doméstico da economia em desenvolvimento são, em algum grau, compensadas pela constituição de arranjos financeiros alternativos. Porém, nos períodos de queda cíclica da liquidez mundial tais arranjos tornam-se inoperantes (Resende, 2005), trazendo à tona as deficiências do sistema financeiro da economia em desenvolvimento, que se manifestam na elevada restrição de financiamento de longo prazo. Esta lacuna do sistema financeiro da economia em desenvolvimento implica a queda da taxa própria de juros dos ativos associados a incerteza elevada e longo prazo de maturação. Assim, a consequente queda do investimento em FBKF e em inovações tecnológicas se somam para mitigar o amadurecimento do SI, nas economias em desenvolvimento.

Deste modo, as deficiências do sistema financeiro da economia em desenvolvimento, entre as quais se destaca a ausência de financiamento privado de longo prazo, afetam de duas maneiras o desenvolvimento de seus SI: I) de um modo direto, por prejudicarem o financiamento das atividades inovativas, visto que estas estão associadas a um elevado grau de incerteza e longo prazo de maturação; II) de um modo indireto, porque contribuem para inibir o investimento (FBKF), principalmente nos períodos de queda cíclica da liquidez mundial, sendo que a FBKF é condição necessária para o desenvolvimento do SI (Nelson, 2005; Dosi et al., 1994).

Todavia, há mais um fator, além destes, que mitiga o desenvolvimento do SI nas economias em desenvolvimento: mesmo na presença de um sistema financeiro doméstico desenvolvido, o próprio grau de amadurecimento do SI afeta as condições de financiamento das atividades inovativas, reforçando o círculo vicioso da Figura 1. Dado o caráter cumulativo (trajetória de dependência) do progresso tecnológico, o baixo grau de desenvolvimento do SI contribui para aumentar ainda mais a incerteza associada às atividades inovativas, principalmente no que se refere ao êxito e retorno do investimento em inovação tecnológica. Isto reduz a taxa própria de juros dos ativos relacionados às atividades de inovação tecnológica (ativos inovativos), o que inibe a alocação da riqueza da sociedade nestes ativos e contribui para perpe- 
tuar as diferenças de amadurecimento entre os SI das economias desenvolvidas e em desenvolvimento (quadrante superior esquerdo da figura 2).

Portanto, o círculo vicioso que perpetua o baixo grau de desenvolvimento relativo do SI nas economias em desenvolvimento é reforçado quando se consideram as deficiências do sistema financeiro dessas economias no âmbito do modelo de escolha de ativos. A perpetuação do caráter imaturo do SI das economias em desenvolvimento desemboca no elevado grau de sua vulnerabilidade externa estrutural. Disto resulta o comportamento assimétrico, ou minskyano, do sistema financeiro internacional, tornando os ciclos de crescimento dessas economias mais aderentes aos ciclos de liquidez mundial em relação as economias centrais, cujo SI é maduro. O comportamento assimétrico do sistema financeiro internacional, favorável às economias com SI consolidados, ajuda a ampliar o hiato de crescimento entre "centro" (economias com SI maduro) e "periferia" (economias com SI imaturo). Esta conclusão está de acordo com a tese pós-keynesiana de que o sistema financeiro (internacional) não é neutro e afeta o desenvolvimento e o crescimento das economias de modo desigual (Dow, 1993, cap 11).

Assim, essa articulação entre as duas correntes teóricas (pós-keynesiana e neo-shumpeteriana) pode explicar importantes obstáculos para o crescimento de longo prazo dos países em desenvolvimento. A partir de tal articulação demonstrou-se, também, que o investimento e, portanto, os ciclos de crescimento dessas economias dependem em um grau não desprezível dos ciclos da liquidez internacional.

As relações causais entre Sistma Financeiro Internacional (SFI), sistema financeiro doméstico e SI apresentadas neste trabalho e que ensejam o processo de causação circular da Figura 2, podem ser corroboradas pelas características dos ciclos de crescimento das economias em desenvolvimento. Cite-se, por exemplo, diversas economias latino-americanas que sofreram recorrentes crises cambiais ao longo do século passado. O Brasil pode ser tomado como exemplo visto que, mesmo sendo o país mais desenvolvido da América Latina, não possui um SI maduro e as reversões cíclicas de seu crescimento econômico em todo o século XX sempre estiveram associadas a restrição de divisas externas e crises cambiais que romperam os arranjos financeiros de sustentação de seu crescimento, segundo está detalhado em Resende (2005).

\section{CONCLUSÃO}

Este artigo procurou demonstrar por meio das literaturas evolucionária e pós keynesiana as relações causais entre o sistema nacional de inovações (SI) e o sistema financeiro nacional e internacional. Visou-se, com isso, explicar a aderência dos ciclos das economias em desenvolvimento aos ciclos da liquidez internacional.

A partir da construção de uma "ponte" entre a abordagem evolucionária do SI e o modelo de escolha de ativos de Keynes argumentou-se que na economia em desenvolvimento há um circuito de causação circular que contribui para: I) perpetuar o caráter imaturo do seu SI; II) perpetuar sua vulnerabilidade externa; e, III) ensejar a aderência de seus ciclos aos ciclos da liquidez internacional Deste modo, o artigo contribui teoricamente para o debate sobre as especificidades dos ciclos das economias em desenvolvimento e suas diferenças com os ciclos das economias desenvolvidas. 
O rompimento do citado circuito depende do amadurecimento do SI das economias em desenvolvimento, o qual depende, entre muitos outros fatores, do acesso ao financiamento das atividades inovativas, presentes no SI. A discussão teórica desse ponto sugere o sistema financeiro como parte integrante do sistema nacional de inovações. Ou seja, ter desenvolvimento científico e tecnológico implica em ter um sistema financeiro desenvolvido e vice-versa.

\section{REFERÊNCIAS BIBLIOGRÁFICAS}

ABRAMOVITZ, M. (1986) "Catching up forging ahead and falling behind", Journal of Economic History, v. 46, n. 2, p. 386-406.

ALBUQUERQUE, E. M. (1999) “National systems of innovation and Non-OECD countries: notes about a rudimentary and tentative "typology", Brazilian Journal of Political Economy, v.19, n. 4, p. 35-52.

ALBUQUERQUE, E. M. (1996a) "Notas sobre a contribuição de Kenneth Arrow para a fundamentação teórica dos sistemas nacionais de inovações”, Revista Brasileira de Economia, v. 50, n. 2, p. 227-242.

ALBUQUERQUE, E. M. (1996b) "Sistema nacional de inovação no Brasil: uma analise introdutória a partir de dados disponíveis sobre a ciência e a tecnologia”, Revista de Economia Política, v. 16, n. 3, p. 56-72.

AMABLE, B.; PETIT, P. (1999) "Identifying the structure of institutions to promote innovation and growth", Working Paper CEPREMAP, n. 9919.

AMABLE. B. ; PETIT, P. (2001) “The diversity of social systems of innovation and production during the 1990s”, disponível em http://www.druid.dk/uploads/tx_picturedb/ds2001-262.pdf.

AMADO, A.M. (2003) "Minsky e o ciclo econômico: uma análise para economias periféricas". In: Anais do VIII Encontro de Economia Política. Florianópolis: Sociedade Brasileira de Economia Política.

BELL, M., E.; PAVITT, K. (1993) “Technological accumulation and industrial growth.” Industrial and Corporate Change, v. 2, n. 2, p.157-211.

CARPENTER, M.; PETERSEN, B. (2002) “Capital market imperfections, high-tech investment, and new equity financing”. The Economic Journal, v.112, n. 476, p.54-72. Apud O'SULLIVAN, M. Finance and innovation. In: FAGERBERG, J.; MOWERY, D.; NELSON, R. The Oxford Handbook of Innovation. Oxford: Oxford University, 2005.

CARVALHO, F.J.C. (1992) Mr Keynes and the Post Keynesians: Principles of Macroeconomics for a Monetary Production Economy. Aldershot: Edward Elgar.

CINTRA, M. A. M. (1999) Uma Visão Crítica Da Teoria da Repressão Financeira. Campinas: Unicamp.

CROCCO, M. (1999) “The Neo-Schumpeterian approach to innovation and Keynes's probability: initial explorations”, Revista de Economia Política, v. 19, n. 4, p. 15-34.

DOSI, G.; FREEMAN, C.; FABIANI, S. (1994) “The process of economic development: introducing some stylised facts and theories on technologies, firms and institutions" Industrial and Corporate Change, v. 3, n. 1, p. 1-45.

DOW, S.C. (1986/87) "Post Keynesian monetary theory for an open economy", Journal of Post Keynesian Economics, v. 9, n. 2, p. 237-257.

DOW, S.C.(1993) Money and the Economic Process. Aldershot, Edward Elgar.

FAGERBERG, J. (1994) "Technology and international differences in growth rates", Journal of Economic Literature, v. 32, n. 4, p. 1147-1175.

FAGERBERG, J., GODINHO, M.M. (2005) "Innovation and catching up", In: FAGERBERG, J.; MOWERY, D.; NELSON, R. The Oxford Handbook of Innovation. Oxford: Oxford University.

FREEMAN, C. (1992) "Formal Scientific and technical institutions in the national system of innovation" In: LUNDVALL, A-B. (Ed.) National Systems of Innovation: Towards a Theory of Innovation and Interactive Learning. London: Pinter: p. 169-187. 
FREEMAN, C. (1995) “The "National System of Innovation" in historical perspective". Cambridge Journal of Economics, v. 19, n. 1, p. 5-24.

GERSCHENKRON, A. (1962) Economic Backwardness in Historical Perspective. Cambridge, USA: Belknap.

HALL, B. "The financing of research and development". California: University of California, 2002. (Working Paper NBR) apud O'SULLIVAN, M. Finance and innovation. In: FAGERBERG, J.; MOWERY, D.; NELSON, R. The Oxford Handbook of Innovation. Oxford: Oxford University. Cap.9, 2005.

JAYME JR, F. E RESENDE, M.F. (2009) “Crescimento Econômico e Restrição Externa: teoria e a experiência brasileira". In Michel, R. e Carvalho, L (Org) Crescimento Econômico: Setor Externo e Inflação. Rio de Janeiro, IPEA.

KEYNES, J.M. (1937) A teoria geral do emprego. In: SZMRECSÁIYI, T (Org.) Keynes, São Paulo: Àtica, 1999.

KEYNES, J.M. A teoria ex ante da taxa de juros. In: Fundação Instituto de Pesquisa Econômica Aplicada - IPEA. Clássicos da literatura econômica, Rio de Janeiro: IPEA/INPES, 1988b.

KEYNES, J.M. A teoria geral do emprego, do juro e da moeda. São Paulo: Nova Cultural, 1983. 333p.

KEYNES, J.M. Teorias alternativas da taxa de juros. In: Fundação Instituto de Pesquisa Econômica Aplicada - IPEA. Clássicos da literatura econômica, Rio de Janeiro: IPEA/INPES, 1988a.

KEYNES, J.M. The general theory: part I — preparation. Cambridge: Macmillan, 1973. v.12

LOPEZ, J. México's Crisis: Financial Modernization and Financial Fragility. Banca Nazionale Del Lavoro Quartely Review, Rome, v.50, n. 201,p. 165-185, Jun. 1997.

LUNDVALL, A-B. (Ed.) National Systems of Innovation: Towards a Theory of Innovation and Interactive learning. London: Pinter. 1992.

MADDISON, A. Dynamics Forces in Capitalist Development. New York: Oxford, 1991.

MADDISON, A. "Long run dynamics of productivity growth". Banca Naz. Lavoro Quarterly Rev., Rome, v. 32, n. 128, p. 3-43, Mar. 1979.

MADDISON, A. Phases of Capitalist Development. New York: Oxford, 1982.

MINSKY, H. P. Stabilizing and Unstable Economy. New Haven: Yale University, 1986.

NELSON, R. (Ed.). National Innovation Systems: A Comparative Analysis. New York: Oxford University, 1993.

NELSON, R. "Institutions supporting technical change in the United States". In: DOSI, G. (Ed.) et al. Technical change and economic theory. London: Pinter, 1988. p. 312-329.

NELSON, R.; WINTER, S. An Evolutionary Theory of Economic Change. Cambridge: Harvard University, 1982.

NELSON, R.; WINTER, S.(2005) Uma teoria evolucionária da mudança econômica. Campinas/SP: UNICAMP.

O'SULLIVAN, M. Finance and innovation. In: FAGERBERG, J.; MOWERY, D.; NELSON, R. The oxford handbook of innovation. Oxford: Oxford University, 2005. Cap.9, p. 240-265.

PAULA, L. F. R. (1999) “Teoria da firma bancária”, In: LIMA, G.T.; SICSÚ, J.; PAULA, L.F.R. (Orgs.). Macroeconomia moderna: Keynes e a economia contemporânea. Rio de Janeiro: Campus, p.171-189.

RAPOSO, D.A.T. (2009) Liquidez Internacional e Crescimento Econômico: Uma Análise Pós-Keynesiana Da Experiência Mundial. 2009. Tese (Doutorado em Economia), Universidade Federal de Minas Gerais (Cedepar), Belo Horizonte.

RESENDE, M.F.C. O (2005) "Padrão dos ciclos de crescimento da economia brasileira: 1947-2003", Economia e Sociedade, v.14, n.1, p.109-129.

RESENDE, M.F.C e AMADO, A. (2007) "Liquidez internacional e ciclo reflexo: algumas observações para a América Latina”, Revista de Economia Política, v.27, n.1 (105).

SICSÚ, J. \& ALBUQUERQUE, E.M. (1998) "Financiamento do investimento em P\&D, risco e seguro: uma abordagem não-convencional”. Revista Brasileira de Economia, 52(4): pp.675-696.

SICSÚ, J. \& ALBUQUERQUE, E.M. (2002) “As atividades de P\&D e o sistema financeiro. Revista de Economia Politica, 22(2): pp.119-35, 2002.

STUDART, R. (1995) Investment Finance in Economic development. London: Routledge.

VEBLEN, T. (1915) Imperial Germany and the Industrial Revolution. New York: Macmillan. 